\title{
The Impact of Setting Goals in Elementary Classrooms
}

\author{
Sarah R. Edwards Moore \\ Susquehanna University, United States
}

\begin{abstract}
This article looks at how the self-regulated learning strategy of setting goals was used by seven pre-service teachers during their student teaching semester. Goals were set by student teachers throughout the semester during seminar classes. Each goal was set and reflected on before a new goal was determined. Findings indicate that pre-service teachers focused on improving either the management of their classrooms or pedagogy. The pre-service teachers reflected that setting a goal and thinking about a way to achieve the goal made positive impacts on their teaching practice. Implications of this study will be useful to teacher education programs and pre-service teachers in field placements.
\end{abstract}

\section{Introduction}

Pre-service teachers should be prepared to provide their students with the ability to achieve academic successes and apply strategies to learn. The combination of these challenges make self-regulated learning important [1]. Successful teachers must be reflective and analytical about their own beliefs and practices and acquire a deep understanding of cognitive and motivational principals of learning and teaching. Self-regulated learning is characterized by awareness of thinking, use of strategies, and situated motivation. Teachers must experience, construct and discuss these features in order to understand how to nurture the same development among students [2].

A self- regulated approach that provides teachers with the chance to understand their classrooms and instruction more deeply is associated with being a reflective practitioner [3], [4], [5]. Being reflective means the teacher has the ability to engage in active, persistent analysis of his or her beliefs and knowledge and the consequences that follow from those beliefs and knowledge. Self-regulated learning is related to being a reflective practitioner because teachers need to be able to know more about their own thinking, develop effective strategies and sustain their own motivation if they hope to make their own classrooms spaces where students can also be reflective about learning [6]. The more teachers understand about their own thinking, the more they can model reflection for their students.

One way a pre-service teacher can be a reflective practitioner and self-regulated learner is by setting goals. The practice of goal setting is more effective when an individual set their own goal that is appropriate and attainable [7]. Furthermore, goal setting has been found to help learners reach positive outcomes academically [8] and it helps learners respond to challenges [9]. For example, when a task has been completed poorly or an obstacle is encountered, the self-regulated learner is willing and able to start over with a better plan. They have constructive failure meaning that they realize it is the response to failure, not failure itself that is important [10], [11].

Pre-service teachers who are experiencing their student teaching semester need to be given the space to reflectively set goals that will help them identify the challenges they are facing and try to implement strategies that will help them respond to failure effectively. The literature pertaining to selfregulation and teaching predominately looks at how current practitioners are reflecting in their classrooms and how they are having their students reflect. There is a lack of self-regulation research that looks the impact of self-regulated goal setting on the student teacher's practice. It is important to look at the ways that student teachers are setting goals reflectively for a few reasons. First, it allows teacher educators to see what issues student teachers are most concerned about. Second, it allows pre-service teachers to see what other students in the field are choosing to be reflective about in their practice and what strategies they are using to combat challenges. Finally, it provides context to the larger field of education about the power of goal setting and reflection in the student teaching semester. 


\section{Methods}

The participants in this study were seven student teachers from a small liberal arts college in the Eastern United States. The student teachers were in their spring semester where they student teach for five weeks in a Pre-K setting and they student teach for ten weeks in an elementary setting grades K-4. As part of the spring semester course work student teachers are required to attend a seminar class. In each seminar class each of the seven student teachers received a reflection sheet that had them first reflect on goal they set during the previous seminar class and record what impact, if any that the set goal had on their student teaching practice. The student teachers would then set a new goal. Throughout the course of the semester the student teachers were able to set and reflect on goals five times in conjunction with when the seminar classes met. After the data was collected it was analyzed in order to determine first what type of goals student teachers were setting. Each of the reflections was labeled according to each of the student teacher participants (Student Teacher 1 to 7 ).

The analysis found that the student teachers were setting either Management goals or Pedagogy goals and the data was coded to reflect this. Secondly, the data was analyzed to see what type of impact the goals had on the student teacher's practice. Three themes emerged from the Management goals and four themes emerged from the Pedagogy goals. In regards to the Management impact, goal setting led to further reflection, teacher confidence, and increased student focus. Pedagogy goals impacted more supervisor feedback, lesson efficiency, establishing new habits, and teacher preparedness. Each of the themes will be presented in the findings section below.

\section{Findings the Impact of Management Goals}

As stated in the Methods section, the student teachers set goals in order to help them manage things in the classroom. For instance goals were set to help manage classroom behaviors such as noise and talking. The management goals led student teachers to reflect more, increase their confidence, and it helped their students stayed more focused. Below examples of the impact of the management goals will be shown in the order of further reflection, teacher confidence, and student focus.

\subsection{Further Reflection}

For a few of the student teachers, setting management goals led them to be able to reflect on if the goal was working and actually led them to discover a management tool that would work. Below are three examples of how goal setting led to further reflection

3.1.1. Student Teacher 5 Goal: I want to reduce unwanted noise and talking.

Strategy: On the board I want to have NOISE posted and when it becomes too loud, I will erase a letter and once it is down to NO, the students will owe recess.

Impact: Instead of NOISE on the board, I decided to use a computer program called bouncy balls that reacts to the noise in the room. It has been a really big help because the students try to not make the balls bounce and it keeps them focused. It has really made my classroom management better.

3.1.2. Student Teacher 6 Goal: I want to work on referencing my behavior plans (group \& individual) to my class.

Strategy: I am going to put post it's up where I put my materials during a lesson.

Impact: Honestly, I barely remembered this system until I was up at the front of the room teaching already, I think something that would work better could be a note/ding on my phone to vibrate/sound every few minutes. Another option would be to put rubber bands or hair bands on one wrist like 3 or 4 and then switch them over to the other wrist every time I mention a behavior plan.

3.1.3. Student Teacher Goal 4: I want to control my students during large group.

Strategy: I created a daily behavior log

Impact: This worked wonderfully and has been perfect for documenting what is happening.

\subsection{Teacher Confidence}

Some of the student teachers impacted their confidence level as a result of setting management goals that helped them manage their wellness and independence in the classroom. Below are four examples of how teacher confidence was impacted through goal setting.

3.2.1. Student Teacher 3 Goal: I need to work on staying inspired.

Strategy: I set up a daily inspirational post app on my phone. Every day, my phone sends me an 
inspirational quote to guide me through each day of student teaching. I also put post it notes next to my bedside table about getting through each day with a positive attitude.

Impact: It did work! I was excited for my inspirational quote every day. I don't think I could have gotten through these past few weeks without them. My post it's helped me to have a more positive mindset every day.

3.2.2. Student Teacher 7 Goal: I want to know what is going on in the classroom and begin to be able to have 10 eyes. I want to not rely on my co-op when issues arise between kids.

Strategy: I want to write down what seems to work with certain students. I want to use consistent strategies and follow through. For Example, if I say I will take it away, I want to make sure to take it away. I want to not look for co-op, just deal with issues.

Impact: I was more consistent and wrote down good things I saw students doing. Then, during circle I saw what was good (gave good examples of what I expect and bad examples of what students were doing). Students started coming to me and I was able to figure out how to handle different situations (kids fighting, a situation in special).

3.2.3. Student Teacher 6 Goal: I want to take some time to write down the most important notes and lessons that I want to take with me.

Strategy: These are things I want to post around my apartment now and eventually bring them into a classroom as inspiration.

Impact: I liked this idea because it motivated and inspired me, kept me on track day to day.

3.2.4. Student Teacher 1 Goal: I would like to work on different management and behavior strategies.

Strategy: Made a list of different management and behavior strategies, hung it up in group area and circle time area so that I can get students attention and manage their good and bad behavior

Impact: I ended up using different attention grabbers for my management and behavior strategies. I also remembered to use the pompom jar and other positive behaviors more. I think that this also helped to improve my teacher voice.

\subsection{Increased Student Focus}

Setting management goals helped some student teachers find a way to focus their student's attention more and therefore promoted greater efficiency and student responses within lessons. Below are a few examples of the impact management goals had on student focus.
3.3.1. Student Teacher 3 Goal: I want to work on behavior management during lessons so that it doesn't take away from lessons.

Strategy: I want to give wait time between specific instructions to prevent distraction and create more on-task behavior

Impact: Yes this worked. Students had more on task behavior and it saved me a lot more time because I was not correcting behavior as much.

3.3.2. Student Teacher 7 Goal: I want to get more students' attention.

Strategy: Using hands on top, everybody stop and talking quiet and other attention strategies. I want to have a notecard of different ways to grab attention.

Impact: Pre-K ended really nicely. The students got better at responding. I used my voice (louder, hands on top) lights off- silent command worked to. I started singing and they sang along.

\subsection{The Impact of Pedagogy Goals}

The second types of goals that student teachers in the study tended to set were related to their pedagogy. The student teacher's wanted to improve their instructional practice and set goals that helped them make progress within their lesson plans and academic instructional delivery. As a result, the student teacher's received more positive feedback from their supervisors, had greater lesson efficiency, changed some of their habits, and improved their teacher preparedness. Examples of the student teacher's reflections are below that demonstrate the impact of their set goals. The examples are organized according to the themes of supervisor feedback, lesson efficiency, and changed habits.

\subsection{Supervisor Feedback}

For some of the student teachers, setting goals in regards to their instructional practices was measured by the feedback that they received from their supervising teachers. Below are two examples that demonstrate how supervisor feedback became the impact measure for a set goal.

3.5.1. Student Teacher 4 Goal: I want to manage time and level my lessons.

Strategy: Be more prepared the day of the lesson and not prepping that morning.

Impact: I was praised for being on top of my lessons by my co-op

3.5.2. Student Teacher 6 Goal: I want to support my lower level students during guided reading. 
Strategy: I want my co-op teacher to be my resource and watch me when I am conducting lesson. I also want to use the paper of resources my teacher gave me.

Impact: My group still gives me some trouble but it is getting better. I realized based on feedback from my co-op teacher that I need to meet with them longer, doing a picture walk, and going over vocabulary is all the more intensive with them.

\subsection{Lesson Efficiency}

Some of the student teachers wanted to improve certain aspects of their instructional practice and set goals accordingly. Below are three examples of the impact set goals had on helping students pay attention to content, the details of a lesson plan, and timing within lessons.

3.6.1. Student Teacher 1 Goal: I would like to work on attention grabbers.

Strategy: I will post a list of different attention grabbers in my classroom as well as teach them to the students because right now I am only using two attention grabbers.

Impact: I ended up using one more attention grabber and that was effective. I say Red Robin and the students say, Yum. I want to keep adding in more attention grabbers.

3.6.2. Student Teacher 2 Goal: I need to make my lesson plans much more thorough. I thought I would be able to write shorter plans and know what to do but I am not there yet and I have learned how important it is to write in depth. I want to state the objectives/goals before each lesson and restate them as you go through the lesson.

Strategy: Keep the objective on the board during the lesson and add detail to my plans.

Impact: I put a note on the board stating the objective for Math with an I do, We do, You do reminder. I rewrote the goals on my lesson plans so that when I reviewed them they stuck out to me. The student's started to understand the goals of the lesson and we would discuss the goals together.

3.6.3. Student Teacher 5 Goal: I want to work on time management for lesson plans and activities that go along with the lesson plans.

Strategy: Using post it's, one per day with a to-do posted by my mirror at home with a pencil close to cross off tasks. Once all of the tasks are complete, take it off the wall. I also to put the plans for next week's lessons on an index card in teaching binder in front clear packet. (5)
Impact: The calendars and weekly planning guides have really been a great tool for staying organized and making sure I am completing everything and have all plans in on Thursdays. It has helped me to manage when to teach lessons. For math, I knew to put two lessons together to not have the test on a Monday. The Classroom management reflections help me to know how I am doing with the students.

\subsection{Changed Habits}

A few of the student teachers chose to pick goals that were associated with a habit that they wanted to break as a new educator. Below are four examples of student teachers who ended up replacing an old habit with a new habit after their goals were set.

3.7.1. Sudent Teacher 1 Goal: I would like to work on not saying no.

Strategy: I want to have a list of words to say that are not no and that are more positive that will have a better effect on students.

Impact: I have stopped saying no and started using different words and phrases to direct students in the right direction. For example today a student was putting goldfish crackers on his stuffed animal and instead of just saying no don't do that, I told him that this is not the time and place to be doing that.

3.7.2. Student Teacher 2 Goal: I want to interact with my students before I start teaching instead of just observing from the sidelines.

Strategy: Leaving notes in my notebook and car when I am looking over things or driving to school so I give myself a reminder.

Impact: I felt like I ended up improving how I interacted with my students. I did realize that I would catch myself writing little observations of notes when I should have been walking around and seeing what students were doing.

3.7.3. Student Teacher 3 Goal: I want to feed off of the kids more in guided Math.

Strategy: I will put post it's on the guided math lesson with positive and negative things that I need to remember based on how the kids did during the lesson.

Impact: The post it reminders really helped me; I am starting to write explicit instructions for Math.

3.7.4 Student Teacher 2 Goal: I want to work on a more excited voice when I am giving directions, transitioning, or just talking .

Strategy: Put sticky notes by my backpack and coat reminding me to speak excitedly and to smile. I want to put clip art excited, smiling faces around the room 
Impact: The system worked. I put a note by my bag in the morning reminding me to change the tones of my voice.

\subsection{Teacher Preparedness}

Several of the student teachers selected goals that were associated with teacher preparation, Below are 5 examples of goals that were set that resulted in greater preparation which increased positive pedagogical practice outcomes.

3.8.1. Student Teacher 1 Goal: I would like to work on extra activities for students to so if they finish something early.

Strategy: I will make a list of different activities students can do if they finish something early

Impact: The list worked well. It provided me and the students with things they can do if they finish something early. They could read, they could color, they could work on their packets at their desk, and more.

3.8.2. Student Teacher 2 Goal: I am teaching language arts at the beginning of this week. I would really like to memorize the language arts routine and not look at the board as much as I did when I started.

Strategy: I plan on highlighting important parts that I will say in the lesson as well as studying lessons more before presenting them.

Impact: I found that highlighting the parts of my lesson plan helped a lot. I would still like to incorporate this highlighting strategy in other parts of the lesson; daily phonics words, vocabulary, and during my read alouds.

3.8.3. Student Teacher 4 Goal: I would like to improve Math meeting and not rely on my co-op as much.

Strategy: I have been trying to prepare my math lesson one day in advance. I think practicing it can really help.

Impact: I think this worked, I am so much more confident in myself. I have come a long way.

3.8.4. Student Teacher 6 Goal: I want to work on time management within 1.5 hours for Math and Science.

Strategy: I am going to bring my daily schedule up to the front of the room with me (has times printed on it) and everytime I move on the the next section/activity, check what time the next one should start.

Impact: I made it do that my stations each took 15 minutes so it was easier to keep track of. This week I am setting a timer because our stations will be shorter.

3.8.5. Student Teacher 6 Goal: Still perfecting my prep time, figuring out what to do the night before, at home, and the morning of (and then what to do when I first get there vs. later).

Strategy: Opposite of my daily schedule, I am writing "before students" to specify what I need to do before the bell... "after students would be what I can do/set up while students are in the room. Finally, I can write "other prep" to specify extra things that I can do ahead of time.

Impact: So I didn't end up keeping all the headings, but I probably would keep the same headings if I had them written or typed ahead of time.

\section{Discussion}

The findings suggest student teachers pick goals around their own management and pedagogy and very rarely picked goals related to reflection or building relationships with students and teachers in the building. Several of the student teachers would pick the same goals every week and very few of the student teachers provide context as to why they picked the goals but they do provide context about if the goal was met and how. Student teachers tended to pick their goals for different reasons. For instance, Student Teacher 3 decided to pick goals that focused on her own mindset in order to help her have a positive school day. Student Teacher 2 aligned her goals as reminders that were directly related to improving her instruction and delivery. Most of the student teachers did not involve anyone else in deciding if their goal was met. They chose to manage their own goals and decide if the goal was met.

Based on the findings, goal setting was beneficial for student teachers in their teaching experience. The student teachers chose to set goals that were related to helping them manage the student teaching experience or the classroom. They also tended to set goals that helped them improve their pedagogical practices. The strategies that most student teachers came up with involved using some type of visual, a prop, or technology. The goals put the student teacher in the position of managing the goal and they were responsible for implementing the strategy that they selected. As a result of setting goals, student teachers were able to see the impact of trying out new strategies and tackling challenges they were facing in their classroom spaces. Goal-setting empowered the student teachers to feel like they had a voice and could come up with concrete strategies to address challenges. The student teachers were able to take 
ownership of the challenges they were facing in their student teaching experiences and work to find solutions. Setting concrete goals and then reflecting on outcomes showed the student teachers that they could measure the results of their efforts.

\section{Conclusion}

This study shows how a group of pre-service teachers were able to improve their teaching practice through self-regulated goal setting. Each participant targeted specific challenges they were facing in their student teaching placement and attempted to alleviate challenges by having a goal. In this case, the goals that were set became ways that the student teachers were able to practice autonomy within their experiences. Goal setting became a chance for the student teachers to have a voice.

This study has implications for the field of education. The findings encourage goal setting to become a regular part of the student teaching experience and the fact that the student teacher was accountable for reflecting on the impact of the goal after it was set suggests that supervisors and professors should help student teachers become accountable for the goals that they set. This study looked at a small group of student teachers and did not attempt to influence what type of goals the student teachers were setting. Future studies could look at a larger number of student teachers and may want to concentrate the student teacher's goal setting on an identified area of improvement that has been highlighted by both the student teacher and supervisor. It would also be beneficial to see if the student teachers involved in this study continued to set goals and reflect on the progress of goal setting after graduation.

\section{References}

[1] Lenne, D., Abel, M., Trigano, P., \& Leblanc, A. Selfregulated learning in technology enhanced learning environments: An investigation with university students. Technology, Pedagogy and Education, 2008, 17(3): 171181.

[2] Paris, S. G., \& Winograd, P. W. (1990). How metacognition can promote academic learning and instruction. In B.J. Jones \& L. Idol (Eds.), Dimensions of thinking and cognitive instruction (pp.15-51). Hillsdale, NJ: Lawrence Erlbaum

Associates

[3] Dewey, J. (1933). How we think Chicago: Henry Regnery Co.
[4] Mattern J, Bauer J. Does teachers' cognitive selfregulation increase their occupational well-being? The structure and role of self-regulation in the teaching context.Teaching and Teacher Education. 2014;43(1):5868.

[5] Pietarinen, J., Pyhältö, K., Soini, T., and Salmela-Aro, K. (2013). Reducing teacher burnout: a socio-contextual approach. Teach. Teacher Educ. 35, 62-72. doi: 10.1016/j.tate.2017.05.003

[6] Capa-Aydin, Y., Sungur, S., \& Uzuntiryaki, E. (2009). Teacher self-regulation: examining a multidimensional construct. Educational Psychology, 29(3), 345-356.

[7] Sitzmann, T., Ely, K. (2011). A meta-analysis of selfregulated learning in work related training and educational attainment: what we know and where we need to go. Psychological Bulletin, 137(3), 421-422.

[8] Barnark-Brak, L., Lan, W., \& Paton, V. (2010). Profiles in self-regulated learning in the online learning environment. International Review of Research in Open and Distance Learning, 11(1), 62-80.

[9] Beltman, S., Mansfield, C., \& Price, A. (2011). Thriving not just surviving: A review of research on teacher resilience.Educational Research Review, 6(3), 185207.

[10] Clifford, M. M. (1991). Risk taking: Theoretical, empirical, and educational considerations. Educational Psychologist, 26, 263-297.

[11] Klusmann, U., Kunter, M., Trautwein, U., Ludtke, O., \& Baumert, J.(2008). Teachers' occupational well-being and the quality of instruction:The important role of selfregulatory patterns.Journal of Educational Psychology, $100,702-715$. 